\title{
ORIGINAL ARTICLE \\ Apparent spring swarming beaviour of Lesser Horseshoe Bats (Rhinolophus hipposideros)
}

\author{
Stephen P. Davison ${ }^{1,}{ }^{*}$, Robert J. Thomas ${ }^{2}$
}

\author{
${ }^{1} 16$ Daffodil Lane, Newport, \\ Gwent, Wales, NP10 9Jj. \\ ${ }^{2}$ Cardiff University, Main \\ Building, Park Place, Cardiff, \\ Wales, CF10 3XQ. \\ *Corresponding author: \\ linda@bardon.demon.co.uk \\ DOI: https://doi.org/10.14709/ \\ BarbJ.10.1.2017.03
}

Keywords: Lesser Horseshoe Bats, Rhinolophus hipposideros, swarming behaviour, social swarming, meteorological effects, temperature, rainfall, seasonal variation.

received: June, 23th 2017 accepted: August, 10th 2017

\begin{abstract}
Bat activity is highly seasonal in temperate regions such as the British Isles, due to variation in temperature and food availability, leading to hibernation being commonly used as an overwinter survival strategy. Outside the hibernation season, European species of bats of several genera (Myotis, Barbastella and Plecotus) are known to take part in social swarming behaviours. These typically occur in autumn and are thought to be associated with mating prior to hibernation. Only one British species, the Brown Long-Eared Bat (Plecotus auritus) is known to swarm during spring. In this study, we used a combination of ultra-sonic acoustic monitoring and infra-red video surveillance, to describe seasonal activity patterns of Lesser Horseshoe Bats (Rhinolophus hipposideros) across spring-autumn of two years; 2015 and 2016. We identified a previously unknown spring peak in social activity, which occurred around caves which were known not to be used for hibernation, and occurred several weeks after the bats had emerged from hibernation in each year. Males examined during spring swarming were found to have well-developed epididymides, indicating that these individuals were in reproductive condition. This spring peak of activity is consistent with social swarming behaviour, and to our knowledge is the first record of swarming in this species and genus. We found no consistent evidence of equivalent swarming behaviour in autumn. In addition to the seasonal variation in activity, we detected positive effects of temperature and negative effects of rainfall on Lesser Horseshoe Bat activity, both during the spring swarming event, and across the study period.
\end{abstract}

\section{INTRODUCTION}

In temperate environments, many bat species exhibit seasonal patterns of behaviour, utilising different habitats at different times of the year, often for different purposes. In the case of Lesser Horseshoe Bats (Rhinolophus hipposideros) in the British Isles, bats hibernate over winter in caves, or similar structures, usually within $5-10 \mathrm{~km}$ of their summer home range (Joint Nature Conservation Committee; jncc. defra.gov.uk., accessed August 2017). In summer, female Lesser Horseshoe Bats form maternity colonies, which are generally located in buildings. This species can also utilise transitional roosts when moving between their winter and summer quarters (Schofield 2008). Lesser Horseshoe Bats generally forage in woodland, close to their roosts (Bontadina et al. 2002); the mean distance between foraging areas and roosts is only $2.2 \mathrm{~km}$ (Downs et al. 2016). Mating is thought to occur primarily in autumn, with females storing sperm in the reproductive tract until fertilisation of their eggs in spring (Dietz et al. 2009). However, Gaisler \& Titlbach (1964) recorded storage of sperm in the epididymis of males from autumn to spring, implying that mating and fertilisation may also occur in spring.

All British bat species are insectivorous, and insect availability is generally reduced at lower temperatures (Downs et al. 2016, Peng et al. 1992), so it is not surprising that bat activity is negatively affected by temperature. Indeed, at cold times of the year, bats hibernate as a way of reducing energy expenditure when there is little or no food available (Dietz et al. 2009). Nevertheless, bats may become active on relatively warm winter days (White 1789, Avery 1985, 1986, Downs et al. 2016, S. Davison, personal observations). Lesser Horseshoe Bats have been reported as being active outside the hibernation roost at temperatures above $5^{\circ} \mathrm{C}$ during the winter months in Wales (Robertson 2002). Outside of the hibernation period, Gaisler (1963) reported Lesser Horseshoe Bats in Czechoslovakia leaving roosts to feed at temperatures of $8-9^{\circ} \mathrm{C}$ in April and October.

Several species of bats of different genera aggregate in autumn, in an activity known as "swarming" which is believed to be associated with mating (Fenton 1969, Altringham 2003), and where social behaviour in the form of calling, chasing and copulating has been observed (Thomas et al. 1979). Within Britain, bats belonging to the genus Myotis, Barbastella and Plecotus are involved in autumn swarming (Rivers et al. 2006, Glover \& Altringham 2008) and can travel large distances (at least up to $60 \mathrm{~km}$ in the case of Myotis bats) to meet at "swarming sites". The timing of autumn swarming varies between years in the UK, 
but typically occurs during a relatively brief period during September (Altringham 2003). Such sites typically involve caves that are used by the bats (including for hibernation; Altringham 2003), but the bats do not necessarily enter the cave during swarming, instead being observed flying around the entrance (Rivers et al. 2006), sometimes in multispecies aggregations (Altringham 2003). Among European bat species, the Brown Long-Eared Bat (Plecotus auritus) is the only species known to also swarm in spring, as well as autumn (Furmankiewicz \& Gorniak 2002, Furmankiewicz 2004, 2008). As in other taxa, swarming is thought to be connected with mating in the Brown Long-Eared Bat, as many of the males are in breeding condition, and emit a wide range of call types during swarming (Furmankiewicz et al. 2013).

In the present study we used automated detectors of ultrasonic bat calls to measure nightly activity of Lesser Horseshoe Bats from spring to autumn across two years, and tested for seasonal and overnight patterns in activity, with the aim of extending our understanding of seasonal changes in behaviour of this relatively poorly studied species. Activity was seen to follow a pattern of intense social behaviour in spring that appears to be equivalent to the autumn swarming observed in several other bat species, and the spring and autumn swarming observed in Brown Long-Eared Bats. We also tested for the effects of temperature and rainfall on Lesser Horseshoe Bat activity, with the expectation of greater activity at higher ambient temperatures and lower rainfall.

\section{MATERIALS AND METHODS}

\section{Study area}

Wyndcliffe is a small wooded area on the steep slopes of the River Wye to the north of Chepstow, Wales (latitude $51.671080 \mathrm{~N}$, longitude $-2.6862431 \mathrm{~W}$, Fig. 1). The valley sides are extensively wooded along the $26 \mathrm{~km}$ stretch of the river between the towns of Chepstow and Monmouth. Beyond Monmouth and to the east is further broad leaved woodland, whilst to the west of Chepstow lie other large areas of broadleaved and conifer woodland. In this general area are many livestock farms, most still having grazed fields enclosed by hedges. Wyndcliffe is sited on an area of limestone bedrock, and forms part of a complex of roost sites used by bats around the border between England and Wales. This area contains the largest known concentration of Lesser Horseshoe Bats in the UK (Natural England 2014).

The steep sides of the Wye Valley at Wyndcliffe hold numerous fissures and caves, although these tend to have small entrances. Only four of these caves are large enough for humans to enter, with one, known to the study team as "Hobbit Hole" cave, having a cross section of $800 \mathrm{~mm} x$ $800 \mathrm{~mm}$ which progresses $2.6 \mathrm{~m}$ into the rock. Beyond this, two much smaller passages provide spaces large enough for bats to gain access. This is the cave that has been studied most extensively in the study area, and it is known not to be a hibernation site (based on personal observations during the winter hibernation period, when no bats were found to be present).

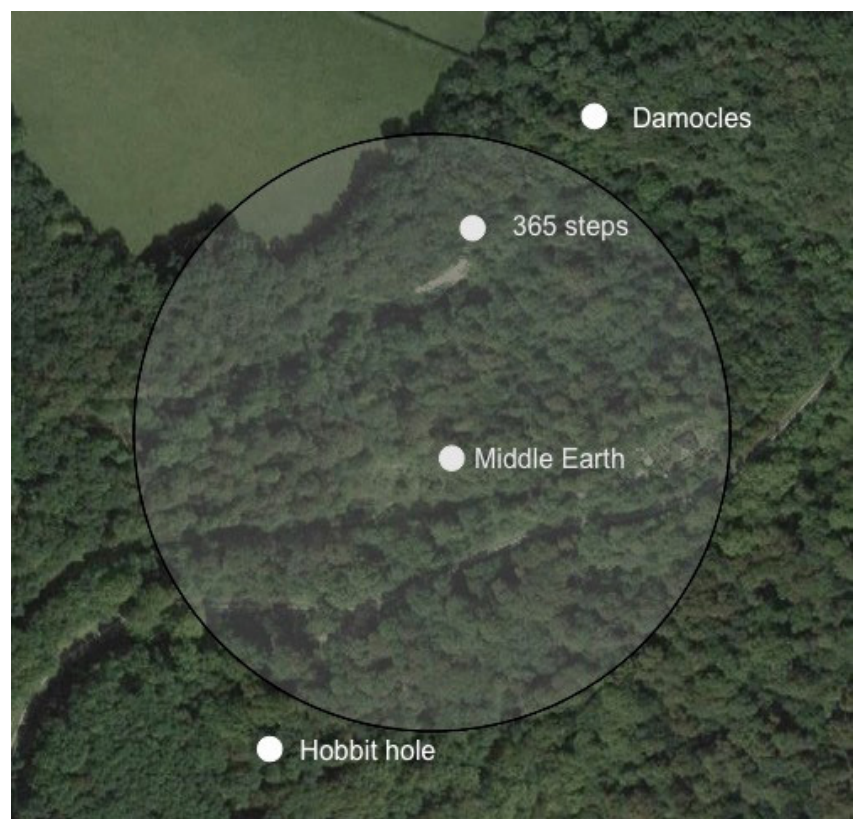

Fig. 1 - Satellite map of the study area, showing the caves mentioned in the text. The shaded circle has a diameter of $1 \mathrm{Km}$. Image created using, RgoogleMaps (Loecher \& Ropkins 2015).

Three other, larger, caves in the area are known to be used for hibernation by both Greater Horseshoe (Rhinolophus ferrumequinum) and Lesser Horseshoe Bats. These caves together are known to the study team as "Middle Earth", "365 Steps" and "Damocles". As the area is heavily wooded, steep and difficult to survey comprehensively, the presence of other caves cannot be ruled out. For example, bats have been seen entering and leaving some of the many fissures in the limestone of the valley sides, which may lead to more extensive -but as yet unexplored- roosting opportunities. Many other known Lesser Horseshoe Bat hibernation sites lie within $10 \mathrm{~km}$ of the site, and two maternity roosts are known within $2 \mathrm{~km}$.

The present study was undertaken in 2015 and 2016. In 2015 we measured bat activity around "Hobbit Hole" between 18 April and 31 October, and compared this with activity in woodland a short distance $(\sim 15 \mathrm{~m})$ from the cave entrance over the same period. In 2016, we monitored bat activity at the same locations between 20 March and 26 November. The study was also extended in 2016 to the wider area of the study site over the same period, to include the caves known as "Middle Earth" and "Damocles". Temperature data was available across the study period of both years, but rainfall data was available only until $17^{\text {th }}$ September in 2016.

\section{Measurement of bat activity}

Bat calls (primarily echo-location calls) were recorded between 15 minutes before sunset, to 15 minutes after dawn, on each night throughout the study season for each year (see above). Lesser Horseshoe Bats typically emerge from their roosts well after sunset (McAney \& Fairley 1988, Schofield 2008, Russ 2012). Hence, it would be expected that the timing of emergence would be covered by the operating schedule of the bat detectors. Indeed, when checked (on several occasions) the detectors did indeed begin recording before bats emerged. 
Bat calls were recorded on a Wildlife Acoustics SM3 Bat Recorder using the "zero crossing" mode (www. wildlifeacoustics.com). This detector has two recording channels; one channel was connected to a microphone set to record bat passes in front of the small cave at "Hobbit Hole", and the other used to record bat passes in the woodland some $15 \mathrm{~m}$ away from the cave. Utilisation of this 2-channel detector minimised the possibility of any differential results from the two sites arising spuriously, due to differences in efficiency of different recorders. In 2016, an Anabat Express detector (http://www.titley-scientific. com) was used at "Middle Earth" and a Wildlife Acoustics SM2 Bat recorder (www.wildlifeacoustics.com) was used at "Damocles". These detectors are different to the SM3 Bat recorder used at "Hobbit Hole", with the possibility that measurement efficiency differs. However, as each site was always monitored with the same type of recorder, the seasonal patterns of activity can be directly compared between the sites.

The number of "zero crossing" files recorded that contained echo-location calls of $R$. hipposideros were used as a proxy for the activity of this species. This measure of activity has been used in many previous studies (e.g. Dzal et al. 2011). In the specific case of the Lesser Horseshoe Bat, its echo location calls of around $110 \mathrm{kHz}$ are unlikely to be confused with any other British bat species, but as the calls are highly focused, detection of bats at distances over 5 metres is unlikely (Barataud 2015). Analysis of the files was undertaken using Analook W software (users.Imi. net/corben). All files containing Lesser Horseshoe Bat echo location calls were manually labelled, and the number of files recorded per hour in the night were counted.

\section{Recording of environmental variables}

Temperature was recorded using a Tinytag Plus 2 TGP 4017 data-logging device (www.geminidataloggers.com). Rainfall data was obtained from the hourly rainfall data for Chepstow (Lat: N 513' 22", Lon: W $002^{\circ} 39^{\prime} 48^{\prime \prime}$ ) available at www.metoffice.gov.uk/public/weather/forecast. Temperature at midnight (GMT) was used in the models of nightly bat activity, with rainfall being analysed on a scale of 1-10, based on the presence or absence of rain at each of ten evenly spaced time points between sunset and sunrise (referred to here as "deciles").

\section{Video recording}

In addition to acoustic monitoring of bat activity, infrared video recording of bat activity was undertaken using a Canon XA10 video recorder in Infra-red mode. The resulting video recordings were inspected visually to assess the nature of the interactions between individual bats.

\section{Examination of bats in the hand}

Fifteen male Lesser Horseshoe Bats were caught under licence during the spring swarming period in April 2017 by S. Davison. The epididymis of each individual was examined as an index of reproductive condition, following Altringham (2003).

\section{Analysis of data}

Analyses were carried out using the statistical software "R" (version 3.2.3. R Development Core Team 2016), and methods followed Thomas et al. (2017). Datasets and annotated R-scripts used for the data analysis presented below, are provided as electronic appendices.

The MASS package (Venables \& Ripley 2002) and the mgcv package (Wood 2011), were used to implement a negative binomial Generalised Additive Model (GAM) analysis of seasonal variation in the number of calls (recorded files) detected at Hobbit Hole on each night in 2015 and 2016, also testing for (and controlling statistically for) the effects of both temperature and rainfall, fitted as linear terms.

A second negative binomial GAM analysis compared seasonal variation in the number of calls at the three monitored caves in 2016 (Hobbit Hole, Middle Earth and 365 Steps), as well as in the woodland just outside Hobbit Hole. This model did not include temperature and rainfall, but modelled seasonal variation at each location using a 2-way interaction between week and location.

A third negative binomial GAM analysis compared the effects of temperature and rainfall on bat activity during the swarming period and non-swarming periods. In this model, season (week), temperature and rainfall were each fitted as non-linear terms, in interaction with a factor coding for swarming / non-swarming periods.

A final negative binomial GAM analysis examined the overnight variation in bat activity during the pre-swarming, swarming and post-swarming periods of 2015 and 2016. Time of night (hours relative to midnight) was fitted as a non-linear term, in interaction with a single categorical variable denoting the season/year combination.

The link function for each model was chosen to minimise the AIC value, as well as normality and homogeneity of residuals. The overdispersion parameter (theta) for each model was chosen to minimise overdispersion (giving a model overdispersion statistic close to 1.0). The residual variation from each model was examined for normality, homoscedasticity and unduly influential observations, following Thomas et al. (2017).

\section{RESULTS}

The Lesser Horseshoe Bat calls recorded were primarily echo-location calls, with a minority of calls recorded at the fundamental frequency of $\sim 55 \mathrm{KHz}$. No social calls were recorded.

In both 2015 and 2016, activity of Lesser Horseshoe Bats around the entrance to "Hobbit Hole" exhibited significant seasonal variation (Fig. 2, P $<0.001$ ) and was, on average, an order of magnitude greater in spring than at other times of the year. The peak of activity occurred approximately 2-3 weeks earlier in 2016 than in 2015; these two years were substantially different in spring temperature, with 2016 being warmer than 2015 in March, April and May respectively. 
A GAM model was used to describe the seasonal variability in bat activity, and to test for the effects of both temperature and rainfall. This model thus allows for the effects of both temperature and rainfall to be examined and controlled for when describing the seasonal variation in bat activity. Rainfall had a significant negative effect on activity, whilst temperature had a significant and positive effect on Lesser Horseshoe Bat activity (Table 1).

The 2016 peak occured approximately 2-3 weeks before that in 2015, probably due to environmental factors as 2016 had a warmer start to the year, with the probable result that bats left hibernation earlier. Nevertheless, there was no statistical difference between the two years in the overall mean level of activity ( $P>0.05$, Table 1$)$.

In 2016, hibernation site surveys were undertaken at Middle Earth (via infra-red video emergence counts), and 365 Steps (via visual inspection). At both sites the majority of Lesser Horseshoe Bats had left the hibernacula by 1 April, well before the peak in activity was measured at Hobbit Hole.

A comparison of activity at Hobbit Hole and in nearby woodland only $15 \mathrm{~m}$ away ( $3 \mathrm{x}$ the detection distance for this species; Barataud 2015) shows significantly more activity at Hobbit Hole than in the woodland $(P<0.001$, Fig. 3, Table 2 ), indicating that the activity is very localised, within $\sim 10 \mathrm{~m}$ of the cave entrance. In addition, activity at Damocles and Middle Earth also show significant variation over the same period (Fig. 4, Table 2). Each of the caves showed significantly higher activity than the woodland adjacent to Hobbit Hole $(P<0.001)$, but were not significantly different in activity compared to Hobbit Hole itself ( $P>0.05$, Table 2$)$. Thus it is clear that the activity of Lesser Horseshoe Bats in the region of Hobbit Hole was high in spring when the bats were more active in the cave area compared to the woodland, and this aggregation at the cave entrances was also shown to extend to two other nearby caves. There was little evidence of a substantial autumn peak in activity at Hobbit Hole in either 2015 or 2016, but both Middle Earth and Damocles showed an autumn peak in activity in addition to their spring peaks (Fig. 4).

Infra-red video recording of bat activity at both Middle Earth and Hobbit Hole clearly showed many occasions of one Lesser Horseshoe Bat chasing another, in a manner reminiscent of Myotis bats during their autumn swarming congregations. Hobbit Hole is not always used as a roost by Lesser Horseshoe Bats; the cave is too small for humans gain access to check for roosting bats, but on four occasions when Hobbit Hole was surveyed (externally) for emergence at dusk, a maximum of four individuals emerged, and on two of the occasions none emerged. On these two occasions, "swarming" still proceeded, indicating that bats were travelling from other roost sites to aggregate around the entrance to Hobbit Hole.

Analysis of activity against temperature and rainfall was undertaken using a negative binomial GAM, with date (week), temperature and rainfall each modelled as smoothed terms, and swarming/non-swarming period modelled as a factor. Activity was positively associated with temperature

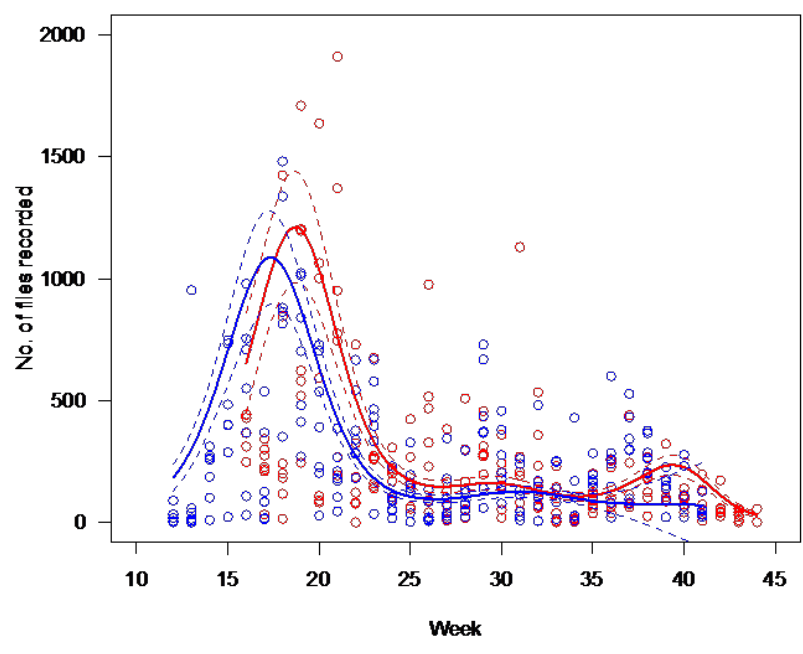

Fig. 2 - Activity of Lesser Horseshoe Bats at "Hobbit Hole" cave in 2015 (red) and 2016 (blue). Each point indicates one nightly total count, with counts compiled into weekly periods.

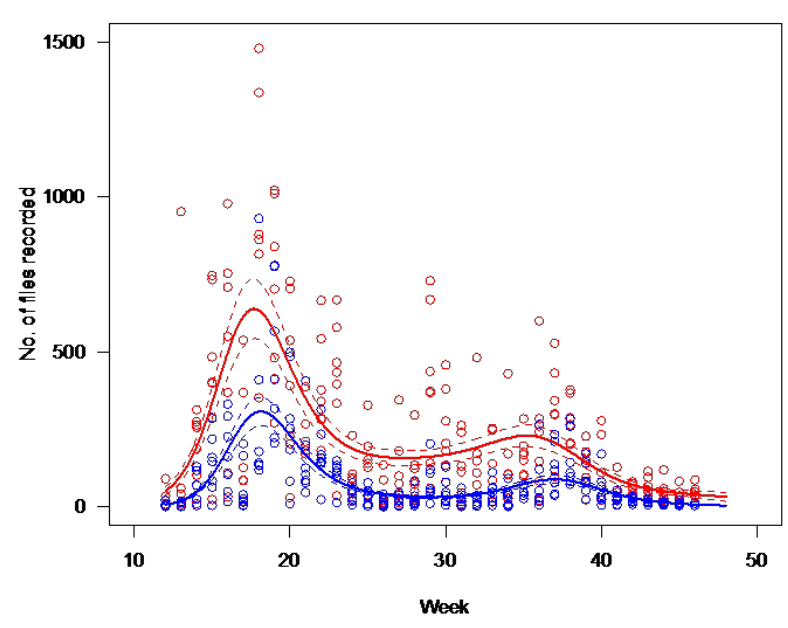

Fig. 3 - Activity of R. hipposideros in 2016, at "Hobbit Hole" cave (red) and in adjacent woodland (blue).

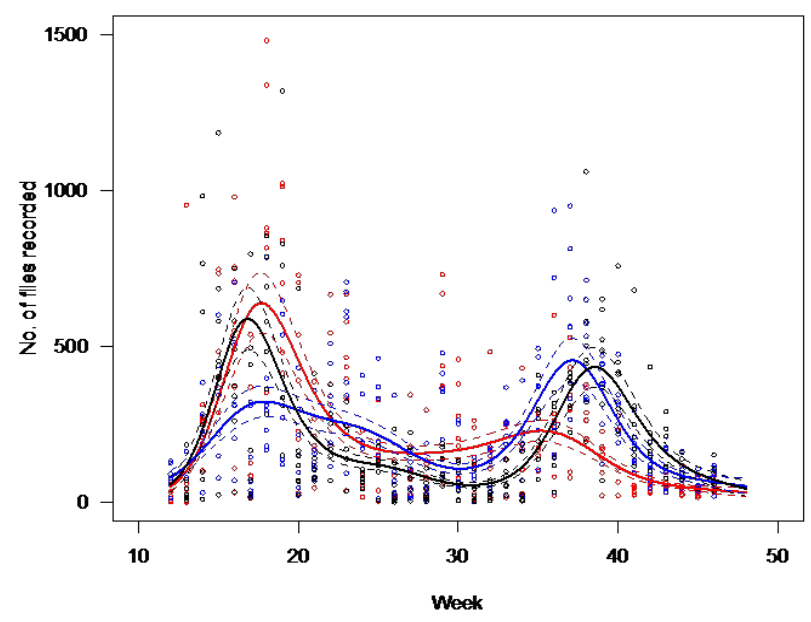

Fig. 4 - Activity of R. hipposideros in 2016, at "Hobbit Hole" (red), "Middle Earth" (blue) and "Damocles" (black) caves. 
Table 1 - A Generalised Additive Model (negative binomial error family and log link function) to explain seasonal variation in activity of Lesser Horseshoe Bats at Hobbit Hole cave in 2015 and 2016. The effects of temperature and rainfall on bat activity were also examined. Overdispersion parameter $=1.25$, overdispersion statistic $=0.995$. Deviance explained $=48 \%$.

\begin{tabular}{|c|c|c|c|c|c|}
\hline Parametric coefficients: & Reference level & Estimate & SE & $\mathbf{z}$ & $\mathbf{P}$ \\
\hline Intercept & - & +3.751 & 0.283 & 13.263 & $<0.0001$ \\
\hline Year (2016) & 2015 & -0.273 & 0.332 & -0.822 & 0.411 \\
\hline Temperature & - & +0.146 & 0.023 & 6.479 & $<0.0001$ \\
\hline Rainfall & - & -0.268 & 0.023 & -11.428 & $<0.0001$ \\
\hline \multicolumn{6}{|c|}{ Non-parametric smoothed terms: } \\
\hline & $\begin{array}{l}\text { Effective degrees } \\
\text { of freedom }\end{array}$ & $\begin{array}{c}\text { Reference degree } \\
\text { of freedom }\end{array}$ & & ii squared & $\mathbf{P}$ \\
\hline \multicolumn{6}{|l|}{ Week x Year } \\
\hline 2015 & 6.289 & 6.727 & & 146.9 & $<0.0001$ \\
\hline 2016 & 4.765 & 5.272 & & 103.1 & $<0.0001$ \\
\hline
\end{tabular}

Table 2 - A Generalised Additive Model (negative binomial error family and log link function) to explain seasonal variation in activity of Lesser Horseshoe Bats in 2016 at four locations: (i) Hobbit Hole, (ii) in woodland immediately outside Hobbit Hole, and (iii) at the nearby caves of Middle Earth and (iv) Damocles. Overdispersion parameter $=1.2$, overdispersion statistic $=1.025$. Deviance explained $=45.2 \%$.

\begin{tabular}{|c|c|c|c|c|c|}
\hline Parametric coefficients: & Reference level & Estimate & SE & Z & $\mathbf{P}$ \\
\hline Intercept & - & +5.176 & 0.059 & 88.109 & $<0.0001$ \\
\hline Site & Hobbit Hole & & & & \\
\hline Woodland & & -1.173 & 0.084 & -14.016 & $<0.0001$ \\
\hline Middle Earth & & +0.100 & 0.083 & 1.199 & 0.231 \\
\hline Damocles & & -0.038 & 0.085 & -0.442 & 0.659 \\
\hline \multicolumn{6}{|c|}{ Non-parametric smoothed terms: } \\
\hline & $\begin{array}{l}\text { Effective degrees Ref } \\
\text { of freedom }\end{array}$ & $\begin{array}{l}\text { rence degrees } \\
\text { of freedom }\end{array}$ & Chi & uared & $\mathbf{P}$ \\
\hline \multicolumn{6}{|l|}{ Week x Site } \\
\hline Hobbit Hole & 6.503 & 6.912 & & .10 & $<0.0001$ \\
\hline Woodland & 6.583 & 6.938 & & .04 & $<0.0001$ \\
\hline Middle Earth & 6.660 & 6.958 & & 96 & $<0.0001$ \\
\hline Damocles & 6.818 & 6.988 & & .09 & $<0.0001$ \\
\hline
\end{tabular}


Table 3 - A Generalised Additive Model (negative binomial error family and log link function) to explain variation in activity of Lesser Horseshoe Bats at Hobbit Hole cave in 2015 and 2016, in relation to season (week), temperature and rainfall (each modeled as smoothed terms) during the swarming and non-swarming periods. Overdispersion parameter $=1.27$, overdispersion statistic $=1.011$. Deviance explained $=48.8 \%$.

\begin{tabular}{|c|c|c|c|c|c|}
\hline Parametric coefficients: & Reference level & Estimate & SE & Z & $\mathbf{P}$ \\
\hline Intercept & - & +5.191 & 0.108 & 48.276 & $<0.0001$ \\
\hline \multicolumn{6}{|l|}{ Swarming/non-swarming } \\
\hline Swarming & Non-swarming & +0.429 & 0.265 & 1.617 & 0.106 \\
\hline \multicolumn{6}{|l|}{ Non-parametric smoothed terms: } \\
\hline & $\begin{array}{l}\text { Effective degrees } \\
\text { of freedom }\end{array}$ & \multicolumn{2}{|l|}{$\begin{array}{l}\text { Reference degrees } \\
\text { of freedom }\end{array}$} & Chi squared & $\mathbf{P}$ \\
\hline \multicolumn{6}{|l|}{ Week x year } \\
\hline 2015 & 6.171 & 6.650 & & 90.40 & $<0.0001$ \\
\hline 2016 & 5.259 & 5.852 & & 49.36 & $<0.0001$ \\
\hline \multicolumn{6}{|c|}{ Temperature x swarming / non-swarming } \\
\hline Non-swarming & 1.741 & 2.212 & & 29.32 & $<0.0001$ \\
\hline Swarming & 1.000 & 1.000 & & 14.95 & 0.0001 \\
\hline \multicolumn{6}{|c|}{ Rainfall x swarming / non-swarming } \\
\hline Non-swarming & 1.000 & 1.000 & & 83.27 & $<0.0001$ \\
\hline Swarming & 1.077 & 1.150 & & 43.29 & $<0.0001$ \\
\hline
\end{tabular}

Table 4 - A Generalised Additive Model (negative binomial error family and log link function) to explain time-of-night variation in activity of Lesser Horseshoe Bats at Hobbit Hole cave in relation to time of night (modeled as a smoothed term) during the pre-swarming, swarming and post-swarming periods of 2015 and 2016. Overdispersion parameter $=0.6$, overdispersion statistic $=1.145$. Deviance explained $=$ $52.7 \%$.

\begin{tabular}{|c|c|c|c|c|c|}
\hline Parametric coefficients: & Reference level & Estimate & SE & $\mathbf{z}$ & $\mathbf{P}$ \\
\hline Intercept & - & +3.135 & 0.157 & 19.951 & $<0.0001$ \\
\hline Period & Pre-swarming 2015 & & & & \\
\hline Pre-swarming 2016 & & -3.487 & 0.584 & -5.967 & $<0.0001$ \\
\hline Swarming & & -0.157 & 0.235 & -0.670 & 0.503 \\
\hline Swarming & & +0.831 & 0.221 & +3.757 & 0.0002 \\
\hline Post-swarming 2015 & & -0.228 & 0.273 & -0.835 & 0.404 \\
\hline Post-swarming 2016 & & -1.553 & 0.334 & -4.652 & $<0.0001$ \\
\hline \multicolumn{6}{|c|}{ Non-parametric smoothed terms: } \\
\hline & $\begin{array}{l}\text { Effective degrees Refer } \\
\text { of freedom }\end{array}$ & $\begin{array}{l}\text { nce degrees of } \\
\text { freedom }\end{array}$ & Chi sq & uared & $\mathbf{P}$ \\
\hline \multicolumn{6}{|l|}{ Hour $x$ Period } \\
\hline Pre-swarming 2015 & 1.841 & 2.281 & 12 . & & 0.0027 \\
\hline Pre-swarming 2016 & 5.889 & 5.989 & 77. & & $<0.0001$ \\
\hline Swarming & $\begin{array}{l}5.117 \\
5.909\end{array}$ & 5.660 & 88. & & $<0.0001$ \\
\hline Swarming & 2.402 & 5.996 & 69. & & $<0.0001$ \\
\hline Post-swarming 2015 & 5.838 & 2.908 & 18. & & 0.0006 \\
\hline Post-swarming 2016 & & 5.986 & 54. & & $<0.0001$ \\
\hline
\end{tabular}


in both the swarming and non-swarming periods $(P<0.001$, Table 3). Activity during the non swarming period is as would be expected by the reports of both Robertson (2002) and Gaisler (1963), in that there is little activity at low temperatures. However, in the swarming period, there was considerable activity at temperatures as low as $5^{\circ} \mathrm{C}$, and some activity below $5^{\circ} \mathrm{C}$ (Fig. 5). Activity was negatively associated with rainfall in both swarming and non-swarming periods ( $p<0.0001$, Fig. $5 b)$.

\section{Time of night of swarming activity}

Activity at Hobbit Hole cave varied significantly with time of night in all years/periods $(P<0.001$, Table 4 , Fig. 6$)$, with a peak in activity in the first part of the night ( 1-2 hours after sunset) evident during the swarming season in both years,

\section{Figure A}

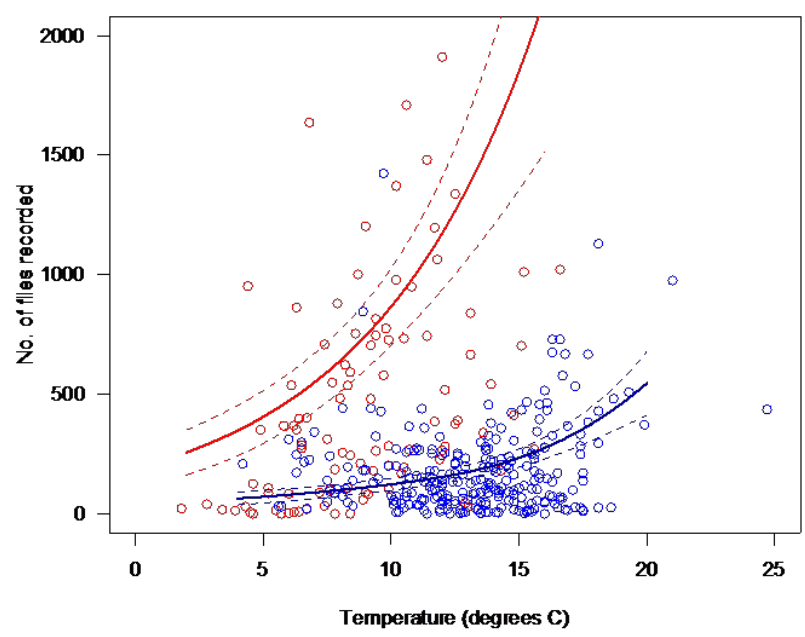

Figure B

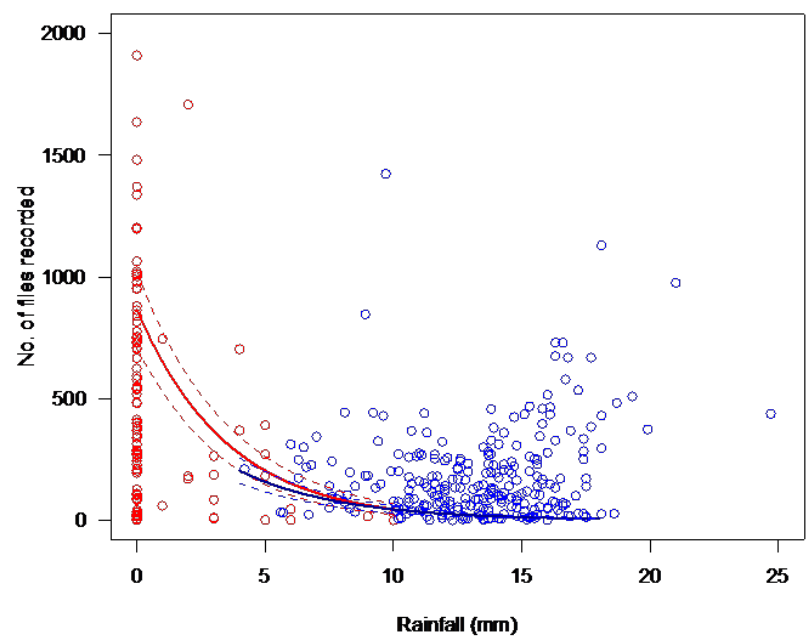

Fig. 5 - Activity of R. hipposideros at Hobbit Hole cave, in 2015 and 2016 , in relation to a) temperature and b) rainfall variation, during the spring swarming period (red), and during the remainder of the active season (referred to as the non-swarming period; blue). and with some evidence of smaller peaks in activity later in the night in 2016 (Fig. 6b).

\section{DISCUSSION}

The seasonal and overnight patterns of activity reveal that Lesser Horseshoe Bats aggregate in the cave areas at Wyndcliffe in spring, primarily in the first half of the night (c.f. activity at summer roost sites, McAney \& Fairley 1988), and the video analysis showed that during these aggregations they frequently engage in chases which resemble those of Myotis bats during their autumn swarming period. Furthermore, the unexpectedly high activity at low temperatures $\left(5-10^{\circ} \mathrm{C}\right)$, and more limited activity below $5^{\circ} \mathrm{C}$, during the spring swarming period, is highly suggestive of this activity not being linked to feeding, due to there being low insect availability at such temperatures (Peng et al. 1992, Downs et al. 2016). Likewise, the aggregations seem unlikely to be the result of bats foraging in darker areas of the study area (cf. Schofield 2008), as two of the locations (Damocles and Middle Earth caves) have open entrances that are not under cover, yet activity at these caves mirror that at Hobbit Hole cave, which is more enclosed.

The low temperatures at which the aggregations occur, the timing (occurring after the bats have already emerged from hibernation), the observations of individuals chasing each other (as is seen in swarming Myotis bats), and the lack of hibernation and roosting use of the Hobbit Hole cave, together indicate that the bats are visiting the cave during spring for primarily social purposes, such as mating, and that the activity is unrelated to emergence from hibernation, or roosting, or feeding. These circumstances suggest instead that these events are some form of social activity, which we speculate is linked to mating in the early spring. An equivalent spring peak of activity has previously been described in Brown Long-Eared Bats (Furmankiewicz 2008).

The number of individual Lesser Horseshoe Bats involved in the swarming aggregations at Wyndcliffe cannot readily be estimated using the methods employed in the present study; a maximum of only three individuals were observed simultaneously on the video footage, but direct observation and licensed captures of bats at the site suggested that the number of individuals was considerably higher. Males are not normally sexually active within their first year (Gaisler 1966), hence we would expect a proportion of the population not to be in reproductive condition at the time of swarming, although it is also possible that immature males do not attend these swarming events.

Of 15 Male Lesser Horseshoe Bats captured in the study area in early April 2017, only one had a partiallydeveloped epididymis, whilst the rest had well developed epididymides, indicating that they had sperm in their epididymis, and hence these individuals were capable of impregnating females. Spermatogenesis in Lesser Horseshoe Bats has previously been reported to occur between May and October, with a peak in July to August (Gaisler 1966), so the sperm in the epididymides of males in April may have been stored from the previous autumn. Whether the result of sperm storage or spring spermatogenesis, the 
Figure A

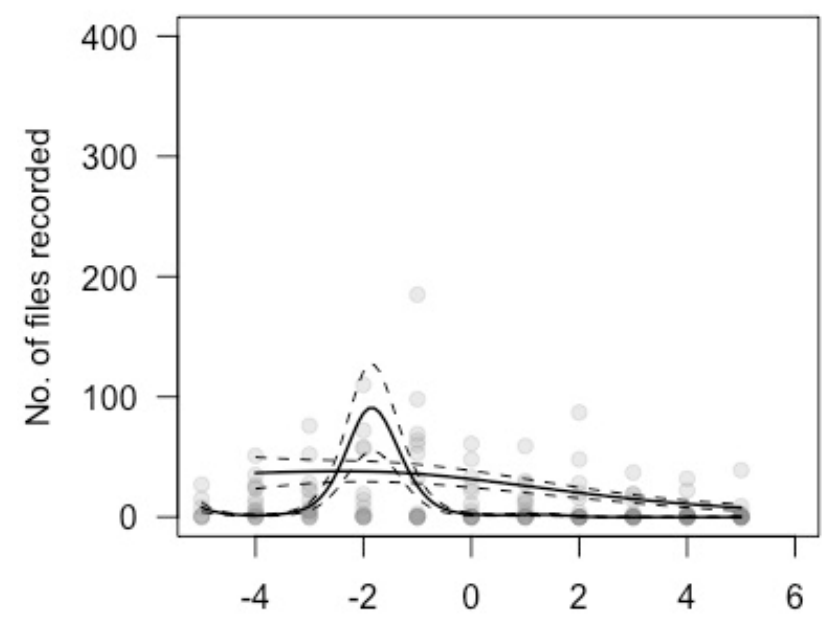

Hours relative to midnight (GMT)

Figure B

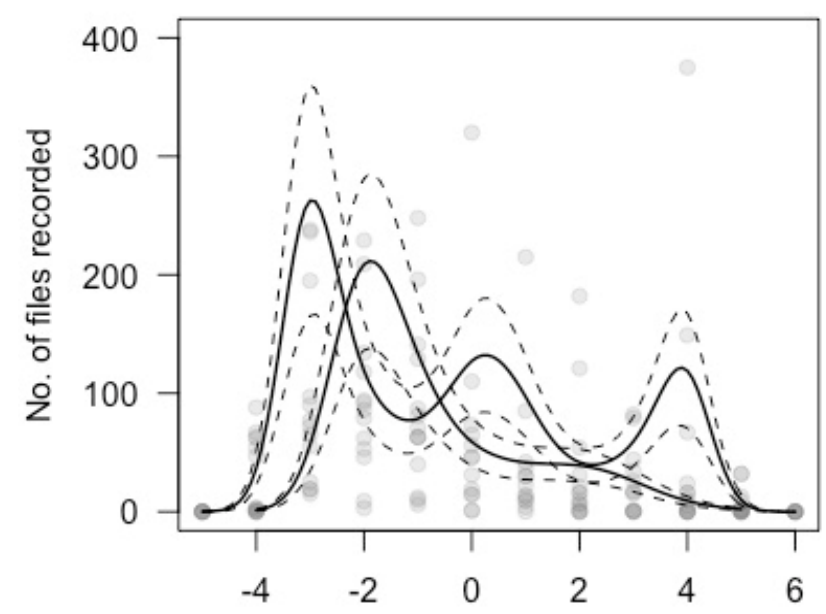

Hours relative to midnight (GMT)

Figure C

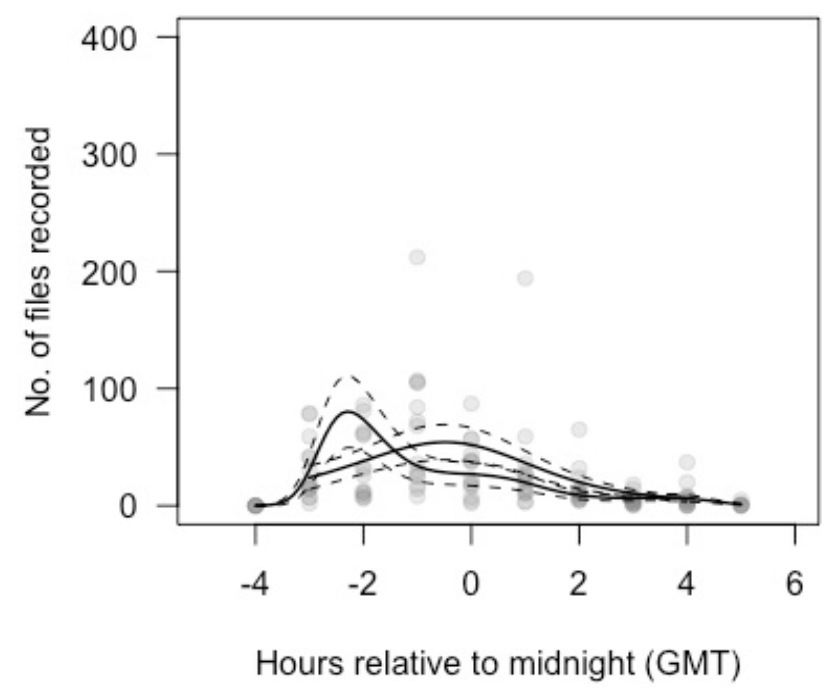

Fig. 6 - Overnight variation in activity of $R$. hipposideros at Hobbit Hole cave during a) Pre-swarming, b) Swarming and c) Post-swarming periods. Separate model-fitted lines are shown for 2015 and 2016. observation of males in apparent breeding condition in April at Wyndcliffe is consistent with the view that the function of the spring "swarming" is related to mating. Whether spring is the primary mating season for Lesser Horseshoe Bats is unknown. Alternatively, the swarming could occur for another social reason, perhaps providing males with an opportunity to advertise themselves ahead of a possible autumn mating peak.

The congeneric Greater Horseshoe Bat (Rhinolophus ferrumequinum) exhibits a mating system based on autumn harems (termed "resource defence polygyny"), which has been extensively described (Rossitor et al. 2002, 2005). Although the Lesser Horseshoe Bat mating system has not been studied in the same detail, it has been thought to be similar (Schofield \& McAney, 2008). The discovery of apparent spring social swarming aggregations in the Lesser Horseshoe Bat reported here, suggests that the two Horseshoe Bat species may have differences in their mating systems after all.

\section{CONCLUSION}

The acoustic data presented in this study, coupled with our infra-red video observations, are highly suggestive of Lesser Horseshoe Bats aggregating in spring around cave entrances, in a form of social activity equivalent to the swarming activity of Myotis bats in autumn. The term "spring swarming" can been used to describe this newly described activity in Lesser Horseshoe Bats.

\section{ACKNOWLEDGEMENTS}

We thank National Resources Wales for access permissions and permits to work on this protected species. Thanks are particularly due to Linda Kergon, Natasha WynneHughes and Steve Wadley for their substantial help in fieldwork, and to James Vafidis for his statistical advice. We are grateful to the editor of Barbastella and two anonymous reviewers for their thoughtful comments and substantial improvements to the manuscript.

\section{REFERENCES}

ALTRINGHAM, J.D. (2003). British Bats. Harper Collins, London, United Kingdom, 218 pp.

AVERY, M.I. (1985). Winter activity of pipistrelle bats. Journal of Animal Ecology 54: 721-738.

AVERY, M.I. (1986). The winter activity of noctule bats (Nyctalus noctula). Journal of Zoology 209(2): 296-299. http://dx.doi.org/10.1111/j.1469-7998.1986.tb03590.x

BARATAUD, M. (2015). Acoustic Ecology of European Bats: Species Identification, Study of their Habitats and Foraging Behaviour. Biotope, Paris, France, 349 pp.

BONTADINA, F., SCHOFIELD, H. \& NAEF-DAENZER, B. (2002). Radio-tracking reveals that lesser horseshoe bats (Rhinolophus hipposideros) forage in woodland. Journal of Zoology 258(3): 281-290. http://dx.doi.org/10.1017/ S0952836902001401 
DIETZ, C., VON HELVERSEN, O. \& NILL, D. (2009). Bats of Britain, Europe and Northwest Africa. A. \& C. Black, London, United Kingdom, 400 pp.

DOWNS, N.C., CRESSWELL, W.J., REASON, P., SUTTON, G., WELLS, D., WILLIAMS, L. \& WRAY, S. (2016). Activity patterns and use of night roosts by Lesser Horseshoe Bats (Rhinolophus hipposideros Borkhausen 1797). Acta Chiropterologica 18(1): 223-237. http://dx.doi.org/10.31 61/15081109ACC2016.18.1.013

DZAL, Y.L., MCGUIRE, L.P., VESELKA, N. \& FENTON, M.B. (2011). Going, going, gone: The Impact of white nose syndrome on the summer activity of the little brown bat (Myotis lucifugus). Biology Letters 7: 392-394. http:// dx.doi.org/10.1098/rsbl.2010.0859

FENTON, M.B. (1969). Summer activity of Myotis lucifugus at hibernacula in Ontario and Quebec. Canadian Journal of Zoology 47: 597-602. http://dx.doi.org/10.1139/z69103

FURMANKIEWICZ, J. \& GORNIAK, J. (2002). Seasonal changes in number and diversity of bat species (Chiroptera) in the Stolec mine (SW Poland), Przyroda Sudetow Zachodnich 2, pp. 49-70.

FURMANKIEWICZ, J. (2004). Social calls and vocal activity of the brown long eared bat Plecotus auritus in SW Poland. Le Rhinolophe 17: 101-120.

FURMANKIEWICZ, J. (2008). Population size, catchment area and sex-influenced differences in autumn and spring swarming of the brown long eared bat Plecotus auritus. Canadian Journal of Zoology 86: 207-216. http:// dx.doi.org/10.1139/Z07-134

FURMANKIEWICZ, J., DUMA, K., MANIAS, K., \& BOROWIEC, M. (2013). Reproductive status and vocalisation in swarming bats indicate a mating function of swarming and an extended mating period in Plecotus auritus. Acta Chiropterologica 15(2): 371-385. http:// dx.doi.org/10.3161/150811013X678991

GAISLER, J. (1963). The ecology of lesser horseshoe bat (Rhinolophus hipposideros hipposideros Bechstein, 1800) in Czechoslovakia, part I. Vestnik Ceskoslovenenske Spolecnosti Entomologicke 27: 211-233.

GAISLER, J. \& TITLEBACH, M. (1964). The male sexual cycle in the lesser horseshoe bat (Rhinolophus hipposideros hipposideros Bechstein 1800). Acta Soc. Zool. Bohemoslov 28: $268-277$.

GAISLER, J. (1966). Reproduction in the lesser horseshoe bat (Rhinolophus hipposideros hipposideros Bechstein 1800). Bijdragen tot de Dierkunde 36: 45-64.

GLOVER, A.M. \& ALTRINGHAM, J.D. (2008). Cave selection and use by swarming bat species. Biological Conservation 141: 1493-1504. http://dx.doi.org/10.1016/j. biocon.2008.03.012
JOINT NATURE CONSERVATION COMMITTEE. (2017, Accessed August).

MCANEY, C.M. \& FAIRLEY, J.S. (1988). Activity patterns of the lesser horseshoe bat Rhinolophus hipposideros at summer roosts. Journal of Zoology 216(2): 325-338. http://dx.doi.org/10.1111/j.1469-7998.1988.tb02433.x

NATURAL ENGLAND (2014, October 1). European Site Conservation Objectives for Wye Valley \& Forest of Dean Bat Sites SAC (UK0014794).

PENG, R.K., FLETCHER, C.R. \& SUTTON, S.L. (1992). The effect of microclimate on flying Dipterans. International Journal of Biometeorology 35: 69-76. http://dx.doi. org/10.1007/BF01208916

R CORE TEAM (2016). R: A language and environment for statistical computing. R Foundation for Statistical Computing, Vienna, Austria.

RIVERS, N.M., BUTLIN, R.K. \& ALTRINGHAM, J.D. (2006). Autumn Swarming Behaviour of Natterer's Bats in the UK: Population size, catchment area and dispersal. Biological Conservation 127: 215-226. http://dx.doi. org/10.1016/j.biocon.2005.08.010

ROBERTSON, J. (2002). Lesser horseshoe bats in a Welsh valley. British Wildlife 13: 412-418.

ROSSITER, S.J., JONES, G., RANSOME, R.D. \& BARRATT, E.M. (2002). Relatedness structure and kin-based foraging in the greater horseshoe bat Rhinolophus ferrumequinum. Behavioural Ecology and Sociobiology 51: 510-518. http://dx.doi.org/10.1007/s00265-0020467-1

ROSSITER, S.J., RANSOME, R.D., FAULKES, C.G., LE COMBER, S.C. \& JONES, G. (2005). Mate fidelity and intra-lineage polygyny in greater horseshoe bats. Nature 437: 408-411. http://dx.doi.org/10.1038/nature03965

RUSS, J. (2012). British Bat Calls: A Guide to Species Identification. Pelagic Publishing, Exeter, United Kingdom, 192 pp.

SCHOFIELD, H.W. (2008). The Lesser Horseshoe Bat Conservation Handbook. Vincent Wildlife Trust, Ledbury, Herefordshire, United Kingdom, 78 pp.

SCHOFIELD, H.W. \& MCANEY, C.M. (2008). Lesser horseshoe bat. In: Mammals of the British Isles: Handbook, Edited by Harris, S. and Yalden, D.W. Mammal Society, Southampton, United Kingdom, 800 pp.

THOMAS, D.W., DENTON, M.B. \& BARCLAY, R.M.R. (1979). Social behaviour of the little brown bat Myotis lucifugus. 1. Mating Behaviour. Behavioural Ecology and Sociobiology 6: 129-136. https://doi.org/10.1007/ BF00292559 
THOMAS, R.J. \& THE GUIDEBOOK TEAM. (2017). Data analysis with $\mathrm{R}$ statistical software: A guidebook for scientists. Eco-explore, Caerphilly, United Kingdom 339 pp.

WHITE, G. (1789). The Natural History and Antiquities of Selborne. Benjamin White, Hampshire, United Kingdom, 320 pp.
WOOD, S.N. (2011). Fast stable restricted maximum likelihood and marginal likelihood estimation of semi parametric generalized linear models. Journal of the Royal Statistical Society (Series B) 73: 3-36. http:// dx.doi.org/10.1111/j.1467-9868.2010.00749.x

VENABLES, W.N. \& RIPLEY, B.D. (2002). Modern Applied Statistics with R. Springer, New York, USA, 498 pp. 